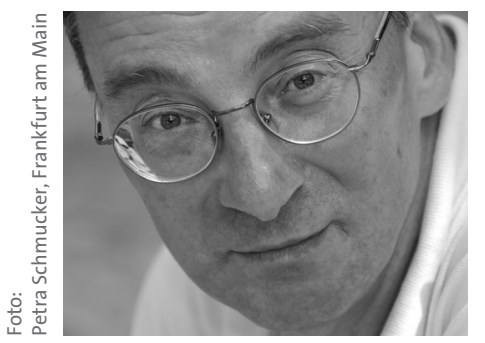

\title{
Zuviel am Zuwenigen
}

»Es fehlt an Vorschriften, ganz recht. Vielmehr es sind zu viel, man wird sie sichten müssen. « Gerichtsrat Walter bringt unsere Ambivalenz gegenüber der Bürokratie auf den Punkt. Die im Lustspiel » Der zerbrochene Krug « von Heinrich von Kleist zutage tretende Widersprüchlichkeit gilt auch in der Sozialwirtschaft. Organisationsmodelle, die auf Selbstorganisation, Vertrauen und ökologischen Prinzipien beruhten, seien exponierte Biotope, von denen man sich bei auftretenden Problemen rasch wieder trenne, meint Wolfgang Gratz in seinem Beitrag zur Bürokratie als unserer »heimlichen Geliebten « in diesem Heft (Seite 12). Man kehre dann zu den vertrauten Monokulturen zurück. Denn Bürokratie funktioniere bei Problemen nach dem Grundsatz: mehr vom selben, also mehr Kontrolle und Normierung. Sie stellten somit hochstabile Systeme dar. Bürokratie sei zudem für Führungskräfte attraktiv, weil sie es ihnen ermögliche, was immer auch geschieht, sich als Teil der Lösung und nicht als Teil des Problems anzusehen. Bürokratische Strukturen stellten Verschiebebahnhöfe dar, in denen die Verantwortung über eine Vielzahl von Weichen nach unten rolle, bis sie am Ort der Leistungserbringung wie an einem Prellbock hängenbleibe.

Der Kampf mit den internen und externen Widrigkeiten für Sozialunternehmen steht auch beim nächstjährigen Kongress der Sozialwirtschaft auf der Tagesordnung. Am 26. und 27. Mai 2011 geht es in Magdeburg darum, wie Verantwortliche den mannigfaltigen Herausforderungen der nächsten Jahre begegnen können. »Den Wandel steuern - Personal und Finanzen als Erfolgsfaktoren « lautet das Schwerpunktthema, das mit Referaten und Diskussionen im Plenum und in zahlreichen Foren beleuchtet werden wird. Eine neue Website mit einer neuen Internet-Adresse - www.sozkon.de - informiert über die aktuelle Kongressplanung und die Teilnahmemöglichkeiten.

Gerhard Pfannendörfer, Chefredaktion 